\title{
Influence of phenylphosphonate based flame retardant on epoxy/glass fiber reinforced composites (GRE): Flammability, mechanical and thermal stability properties
}

\author{
Xiaomin Zhao ${ }^{\text {a }}$, Lingwei Yang ${ }^{\text {a, }}$ Francisco Hueto Martin ${ }^{\text {a }}$, Xiu-Qin Zhang ${ }^{\mathrm{b}}$, Rui Wang ${ }^{\mathrm{b}}$, \\ De-Yi Wang ${ }^{\text {a, * }}$ \\ a IMDEA Materials Institute, C/Eric Kandel, 2, 28906 Getafe, Madrid, Spain \\ ${ }^{\mathrm{b}}$ School of Materials Science and Engineering, Beijing Institute of Fashion Technology, 100029, Beijing, China
}

\section{Keywords}

Polymer matrix

Epoxy reinforced composites

Flammability

Fire retardation

Nanoindentation

\begin{abstract}
In this work, flame-retardant glass fiber reinforced epoxy composites (FGRE) were successfully prepared via adding a novel phenylphosphonate-based flame retardant, $\mathrm{N}, N^{\prime}$-diamyl- $p$-phenylphosphonicdiamide (P-MA) into GRE. FGRE12 showed high LOI value of 33\%. Meanwhile, FGRE12 passed V-0 rating in UL 94 test and the peak of heating release rate (pHRR) decreased by $54 \%$ in comparison with that of GRE. The flame-retardant efficiency of P-MA in GRE was compared with that in epoxy matrix (EP). Moreover, the influences of P-MA on mechanical and thermal stability properties of GRE were studied systemically. Dynamic mechanical analysis (DMA) studied the influence of P-MA on viscoelasticity of GRE. Fiber pushin test and three-point-bending test were used to evaluate the influence of P-MA on the EP matrix/fiber interface strength and interlamilnar shear strength, respectively. In addition, nanoindentation test was used to study the hardness and Young's modulus of EP matrix. The above results showed that the addition of P-MA did not affect the hardness of epoxy matrix and interfacial strength (epoxy matrix/glass fiber). The influence of P-MA on thermal stability of GRE was studied by thermalgravimetric analysis (TGA). These results would be very important in designing new generation multifunctional epoxy-based composite materials.
\end{abstract}

\section{I ntroduction}

In modern society, glass fiber is widely used in order to improve mechanical strength of polymer materials [1]. Glass fiber reinforced composite (GRE) has been applied in many industrial fields due to the high mechanical properties, such as automotive, aircraft, ships, electronic \& electrical appliances and sporting products. However, the intrinsic flammability of epoxy matrix induces potential fire hazard for GRE products. It brings large concern about improving flame retardancy of GRE [2].

The improvement of flame retardancy of GRE was mainly via three kinds of methods: reducing the flammability of epoxy matrix [3e15]; flame-retardant coating method [13]; interfacial intergrowth charring method [8]. Based on reducing flammability of epoxy resin, researchers have tried several organic and inorganic

\footnotetext{
* Corresponding author.

E-mail address: deyi.wang@imdea org (D.-Y. Wang).
}

flame retardants to reduce the flammability of GRE, such as intumescent flame retardant (ammonium polyphosphate and melamine cyanurate) [3], graphene [4], carbon nano fiber [5] and clay [6]. In view of blending flame retardant in epoxy matrix, phosphorusecontaining flame retardant $(\mathrm{P}-\mathrm{FR})$ is considered to be one of most competitive flame retardant for GRE [3,4,9,10]. Kandola [7] reported that pHRR of GRE decreased from $385 \mathrm{~kW} / \mathrm{m}^{2}$ to $278 \mathrm{~kW} /$ $\mathrm{m}^{2}$ and LOI increased by $28 \%$ in presence of commercial melamine phosphate flame retardant Antiblaze NH (4.7 wt\%). In another view of coating flame-retardant layer on surface of GRE, B. K. Kandola et al. studied the thermal barrier influences of one commercial intumescent flame retardant coating (Int.FRC) on GRE by cone calorimeter test [13]. The Int. FRC was a mixture of P-FRs (DOPO, triphenyl phosphate), zinc borate, tetraethylpentamine and $3^{-}$ aminopropyltriethoxysilane. The results showed that intumescent char residue formed by Int. FRC delayed the ignition time of GRE from $36 \mathrm{~s}$ to $96 \mathrm{~s}$, prolonged the combustion time and decreased pHRR by $71 \%$ compared with GRE. In our previous work [9], 
phenylphosphonate based flame retardant exhibited high eff ciency on improving the flame retardancy of diglycidyl ester of bisphenol A based epoxy polymer (EP). With low loading of phos phorous in EP, phenylphosphonate based flame retardant endowed EP with high self extinguishing ability in UL 94 test and signifi cantly decreased the heating release of EP. Under the consideration of reducing the loading amount of flame retardant in EP matrix, high flame retardant GRE was supposed to be developed.

The aim of this work was to develop flame retardant GRE (FGRE) via applying one novel phenylphosphonate based flame retardant, $\mathrm{N}, N^{\prime}$ diamyl $p$ phenylphosphonicdiamide (P MA) in epoxy matrix. The influence of P MA on flammability of EP and GRE were studied by LOI, UL 94 and cone calorimeter test. The influence of P MA on mechanical properties of GRE were discussed in three aspects: i) DMA was used to study the influence on vicoelasticty of GRE; ii) the influence on Young's modulus and hardness of EP were investi gated by nanoindentation test; iii) fiber push in test and three point bending test were used to evaluate the influence of $P$ MA on matrix/fiber interface strength and interlamilnar shear strength of GRE, respectively. In addition, thermal stabilities of these com posites were evaluated by thermal gravimetric analysis (TGA).

\section{Experiment}

\subsection{Materials}

Phenylphosphonic dichloride (PPDCl, 90\%), amylamine (MA, 98\%), diethyl ether and triethylamine (TEA) were purchased from Sigma Aldrich Corporation and used without any further purifica tion. All the chemical regents used in this work were anhydrous. Deionized water was obtained from IMDEA materials laboratory. Epoxy resin (EPC) (epoxy equivalent, 0.54) was purchased from Faserverbundwerkstoffe ${ }^{\circledR}$ composite technology. The curing agent, 4, 4 diaminodiphenylsulfone (DDS) was supplied by Sigma Aldrich Corporation. Glass fiber woven was supplied by the SS laboratory of IMDEA materials institute.

\subsubsection{Synthesis of flame retardant $N, N^{\prime}$ diamyl $p$ \\ phenylphosphonicdiamide (P MA)}

$P$ MA was synthesized according to the rout in Scheme 1. MA $(0.21 \mathrm{~mol})$ and TEA $(0.2 \mathrm{~mol})$ were dissolved in $200 \mathrm{ml}$ diethyl ether at $0-5{ }^{\circ} \mathrm{C}$ in three neck flask. Then into the flask was added dropwise the mixture of $\operatorname{PPDCl}(0.1 \mathrm{~mol})$ and diethyl ether $(100 \mathrm{ml})$. The whole mixture reacted at $0-5{ }^{\circ} \mathrm{C}$ for $2 \mathrm{~h}$ and then the reaction continued at room temperature (RT) for $5 \mathrm{~h}$. After the reaction finished, the solid liquid mixture was filtered off to remove trie thylamine hydrochloride salt and the filtrate was evaporated under vacuum to obtain the crude product of $P$ MA. The product was purified by washing with de ionized water for three times. P MA: yellow liquid $25{ }^{\circ} \mathrm{C}$; yield, 90\%; ${ }^{1} \mathrm{H}$ NMR (DMSO $\left.d_{6}\right): \delta(\mathrm{ppm})$, 7.8-7.4 (ArH, 5H); $5.8(=\mathrm{CH}, 2 \mathrm{H}) ; 5.1-4.9\left(=\mathrm{CH}_{2}, 4 \mathrm{H}\right) ; 3.4\left(-\mathrm{CH}_{2}-\right.$, $4 \mathrm{H}) ;{ }^{13} \mathrm{C}$ NMR (DMSO $\left.d_{6}\right): \delta(\mathrm{ppm}), 137.8,135.5,134.3,131.2,130.6$, 127.8, 114.2, 42.4; ${ }^{31} \mathrm{P}$ NMR (DMSO $\left.d_{6}\right): \delta(\mathrm{ppm}), 19.8$.

\subsubsection{Preparation of EP, GRE, FEP and FGRE}

The preparation of epoxy (EP) and flame retardant epoxy (FEP) followed similar procedure. The weighed P MA ( $5 \mathrm{wt} \%, 8 \mathrm{wt} \%$ and 12 wt\%) was mixed with EPC at $80{ }^{\circ} \mathrm{C}$ for $10 \mathrm{~min}$. Then stoichio metric amount of curing agent DDS was added into the mixture of EPC/P MA step by step after the temperature of mixture rose to $130{ }^{\circ} \mathrm{C}$. The heating stopped until all DDS was dissolved. The final mixture of EPC/P MA/DDS was uniform and transparent. The final mixture was then poured into rubber moulds. The curing procedure was $160{ }^{\circ} \mathrm{C}, 1 \mathrm{~h} ; 180{ }^{\circ} \mathrm{C}, 4 \mathrm{~h}$. The preparation of EP followed the same steps with that of FEP except that the mixing step of EPC/P MA was missed.

The preparation of glass fiber reinforced epoxy composite (GRE) and flame retardant glass fiber reinforced epoxy composite (FGRE) followed similar procedure. First the certain dimension of woven was impregnated with EP or FEP matrix through handed lay up process. Then the certain layers of impregnated woven were cured in hot press machine. The degassing process in vacuum bag was done before curing. Table 1 listed all the formulas of EP, GRE, FEP and FGRE in this work.

\subsection{Characterization}

\subsubsection{Nuclear magnetic resonance (NMR)}

NMR measurements were carried on Varian Mercury AS400 spectrometer which was operated at $400 \mathrm{MHz} .{ }^{1} \mathrm{H}$ NMR, ${ }^{13} \mathrm{C}$ NMR and ${ }^{31} \mathrm{P}$ NMR spectra were collected at room temperature by using tetramethylsilane (TMS) as internal standard and dimethylsulf oxide (DMSO) as the solvent.

\subsubsection{Limiting oxygen index (LOI)}

LOI tested on oxygen index meter (FTT, UK) according to ASTM D2863 97. The sample size was $130 \times 6.5 \times 3.2 \mathrm{~mm}^{3}$.

\subsubsection{Vertical rating test (UL 94)}

Vertical rating test was tested on UL 94 Horizontal/Vertical Flame Chamber (FTT, UK) according to ASTM D3801. The height of burning flame was $20 \pm 0.2 \mathrm{~mm}$. The sample size was $110 \times 12.7 \times 3.2 \mathrm{~mm}^{3}$ in this work.

Table 1

LOI values and UL 94 results of EP, GRE, FEP and FGRE.

\begin{tabular}{|c|c|c|c|c|c|c|}
\hline \multirow[t]{2}{*}{ Sample } & \multirow[t]{2}{*}{ EPC/DDS (g:g) } & \multirow[t]{2}{*}{ GF (wt\%) } & \multirow[t]{2}{*}{ P-MA (wt\%) } & \multirow[t]{2}{*}{ LOI (\%) } & \multicolumn{2}{|c|}{ UL 94 Test } \\
\hline & & & & & Rating & B.L. $^{\mathrm{b}}(\mathrm{mm})$ \\
\hline $\mathrm{EP}$ & $74.6: 25.4$ & 0 & 0 & 22 & $\mathrm{NR}^{\mathrm{a}}$ & 110 \\
\hline FEP5 & $62.7: 32.3$ & 0 & 5 & 32 & V-1 & $25 \pm 3$ \\
\hline FEP8 & $60.7: 31.3$ & 0 & 8 & 33 & V-1 & $24 \pm 4$ \\
\hline FEP12 & $58.1: 29.9$ & 0 & 12 & 36 & $\mathrm{~V}-0$ & $20 \pm 3$ \\
\hline GRE & $46.5: 23.9$ & 29.6 & 0 & 25 & $\mathrm{NR}^{\mathrm{a}}$ & 110 \\
\hline FGRE5 & $43.2: 22.3$ & 30.9 & 3.6 & 29 & $\mathrm{NR}^{\mathrm{a}}$ & $25 \pm 4$ \\
\hline FGRE8 & $42.0: 21.6$ & 30.4 & 6.1 & 31 & $\mathrm{~V}-1$ & $15 \pm 3$ \\
\hline FGRE12 & $39.5: 20.4$ & 30.6 & 9.5 & 33 & $\mathrm{~V}-0$ & $14 \pm 3$ \\
\hline
\end{tabular}

${ }^{a}$ NR meant no rating.

b B.L. meant burnt length.

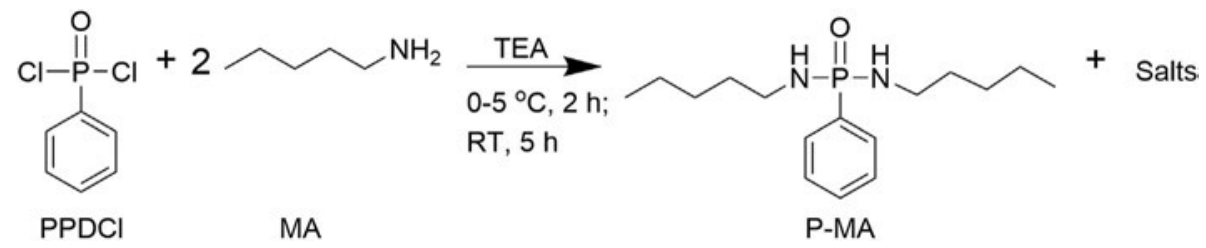

Scheme 1. The synthesis rout of P-MA. 


\subsubsection{Cone calorimeter test}

Cone calorimeter tests were carried out according to the ISO 56601 standard on a cone calorimeter (FTT, UK). Square specimens $\left(100 \times 100 \times 3.2( \pm 0.2) \mathrm{mm}^{3}\right)$ were irradiated at a heat flux of $50 \mathrm{~kW} / \mathrm{m}^{2}$.

\subsubsection{Dynamic mechanical analysis (DMA)}

Dynamic mechanical analyzer Q800 (TA, USA) was employed to evaluate the dynamic mechanical properties of EP, GRE, FEP and FGRE. With a dimension of $30 \times 10( \pm 0.05) \times 2( \pm 0.05) \mathrm{mm}^{3}$, sample was tested from room temperature to $250{ }^{\circ} \mathrm{C}$ (heating rate of $3{ }^{\circ} \mathrm{C} / \mathrm{min}$ ) under single cantilever clamp at $1 \mathrm{~Hz}$ frequency.

\subsubsection{Nanoindentation test}

Nanoindentation was performed on finely polished sample surface in a TI 950 TriboindenterTM (Hysitron, Inc., USA) equipped with a Berkovich diamond indenter. The maximum load was set $10 \mu \mathrm{m}$, large enough to generate a penetration depth more than $1 \mu \mathrm{m}$ to obtain reliable force displacement response. The load time was $5 \mathrm{~s}$, followed with a $2 \mathrm{~s}$ holding time at maximum load to eliminate the thermal drift. The unloading time was also 5 s. A $7 \times 7$ matrice pattern was programmed in a $2 \mu \mathrm{m} \times 2 \mu \mathrm{m}$ areas to acquire representative nanoindentation results. Oliver Pharr method was employed to extract the Young's modulus and hardness of the tested samples from the obtained nanoindentation penetration depth curves $[16,17]$.

\subsubsection{Fiber push in test}

Fiber push in tests were done also in the TI 950 Triboindenter ${ }^{\mathrm{TM}}$ (Hysitron ${ }^{\circledR}$, USA), but using a $5 \mu \mathrm{m}$ flat punch to measure the fiber/ matrix interface shear strength, since the average diameter of $\mathrm{E}$ glass fiber was $\sim 9 \mu \mathrm{m}$. More than 25 tests were performed on selected fibers of the tested sample with a constant displacement rate of $30 \mathrm{~nm} / \mathrm{s}$ and maximum penetration depth of $4 \mu \mathrm{m}$. This loading function allows the generation of fiber de bonding behavior without obvious fiber fracture, which was captured by an in situ optic microscopy. Standard Shear lag model was used to extract the interface interfacial strength from the push in force penetration depth curves [18].

\subsubsection{Three points bending test}

The interlaminar shear strength (ILSS) were studied by means of three point bending tests in macro scale according to the BS EN ISO 14130, on Universal electromechanical testing machine INSTRON 3384 (INSTRON Corp., USA) at a crosshead speed of $1( \pm 0.2) \mathrm{mm} /$ min. The value of ILSS for each specimen was calculated by the formula:

$$
\tau \quad \frac{3 F}{4 b h}
$$

where $\mathrm{F}$ is the load applied; $\mathrm{b}$ and $\mathrm{h}$ are the width and thickness of the test specimen, respectively. In this work the specimen size was $2( \pm 0.2) \mathrm{mm} \times 10( \pm 0.2) \mathrm{mm} \times 20( \pm 1) \mathrm{mm}$.

\subsubsection{Thermogravimetry analysis (TGA)}

The influence of P MA on thermal stability of EP, FEP, GRE and FGRE were performed on a thermogravimetry analysis Q50 (TA, USA) under nitrogen atmosphere. The sample gas purge flow was $90 \mathrm{ml} / \mathrm{min} 25 \mathrm{mg}$ of samples was tested over a temperature range from room temperature to $700{ }^{\circ} \mathrm{C}$ with heating rate of $10{ }^{\circ} \mathrm{C} / \mathrm{min}$. The concentration of glass fiber in GRE was determined through TGA test under air atmosphere during temperature range from RT to $700{ }^{\circ} \mathrm{C}$

\section{Results and discussion}

\subsection{Influence of $P$ MA on the flame retardancy of EP and GRE}

\subsubsection{LOI and UL 94 tests}

LOI and UL 94 tests are two typical small scale tests to charac terize the flammability of plastic materials. The results of LOI and UL 94 tests for EP, FEP (flame retardant EP), GRE and FGRE were listed in Table 1. The videos of UL 94 test of GRE, FGRE5 and FGRE12 were submitted as Supplementary video materials.

Supplementary video related to this article can be found at http://dx.doi.org/10.1016/j.compositesb.2016.10.090.

In epoxy matrix, EP showed low LOI of $22 \%$ and failed in UL 94 test. After $1 \mathrm{st} 10 \mathrm{~s}$ ignition, EP sample burnt out rapidly. These phenomena showed that EP had high fire propagation rate and had no self extinguishing ability once ignited. LOI of FEP increased significantly compared with that of EP. $5 \mathrm{wt} \%$ loading of P MA increased LOI of EP from 22\% to 32\%. FEP12 showed the highest LOI value of 36\%. In UL 94 test, the addition of P MA endowed EP with high self extinguishing ability and sharply reduced fire propagation after ignition. FEP5 passed $\mathrm{V} 1$ rating. The burnt length of FEP5 was only $25 \pm 3 \mathrm{~mm}$ after UL 94 test. FEP12 passed V 0 rating with short burnt length of $20 \pm 3 \mathrm{~mm}$.

LOI of GRE was 25\% which was slightly higher than that of EP. However, GRE also burnt out after 1st ignition and was classified as no rating in UL 94 test. From Table 1 and the test videos of GRE and FGRE in Supplementary materials, the addition of P MA greatly reduced the flammability of GRE. LOI of FGRE increased along with the rising loading of P MA. LOI of FGRE12 was up to 33\%. Compared with that of P MA on LOI of EP, the impact of P MA on LOI of GRE was a little bit lower at the same loading of P MA in EP matrix. For instance, LOI of FEP5 was 32\%, while LOI of FGRE5 was 29\%. In UL 94 test, FGRE also showed self extinguishing ability as well as FEP. FGRE8 passed V 1 rating and FGRE12 passed V 0 rating. The burnt lengths of FGRE8 and FGRE12 were $15 \pm 3$ and $14 \pm 3 \mathrm{~mm}$ respectively, which were shorter than those of FEP8 and FEP12. Overall, flame retardant P MA showed significant influence on reducing the flammability of GRE as well as that on reducing flammability of EP.

\subsubsection{Cone calorimeter test}

Cone calorimeter is one of well known instruments to study the flame retardancy of polymer materials in recent twenty years [19]. In this section, cone calorimeter test was used to evaluate the in fluence of P MA on fire behavior of EP and GRE at $50 \mathrm{~kW} / \mathrm{m}^{2}$ heat flux. The characteristic curves of HRR, total heat release (THR), total smoke production (TSP) and mass vs time were shown in Fig. 1(A, B, $C$ and $D$ ) respectively. The related data were collected in Table 2. They were time to ignition (TTI), peak of heat release rate (pHRR), average effective heat of combustion (Avg. EHC), total heat release (THR), average carbon monoxide yield (Avg. COY), average carbon dioxide yield (Avg. $\mathrm{CO}_{2} \mathrm{Y}$ ) and char residue after test. Fig. 2 showed the residue images of EP, FEP12, GRE and FGRE12 respectively.

In cone calorimeter test, EP was ignited at $53 \pm 2 \mathrm{~s}$. Then the fire behavior was fully developed with a high pHRR of $1076 \mathrm{~kW} / \mathrm{m}^{2}$. This intensive burning terminated within short time of $300 \mathrm{~s}$ as shown in Fig. 1 (A). THR of EP was $91 \mathrm{MJ} / \mathrm{m}^{2}$. Meanwhile, the burning of EP was accompanied by smoke release and mass loss shown in Fig. 1 (C and D). Few residues were remained after the test, showing that EP had low ability to form char residue during burning behavior.

P MA showed remarkable influence on burning behavior of EP in cone calorimeter test. First of all, TTI of EP was shortened due to the addition of P MA. For instance, FEP12 was ignited at $39 \pm 4 \mathrm{~s}$ which was $14 \mathrm{~s}$ earlier than that of EP. Secondly, the developed fire 

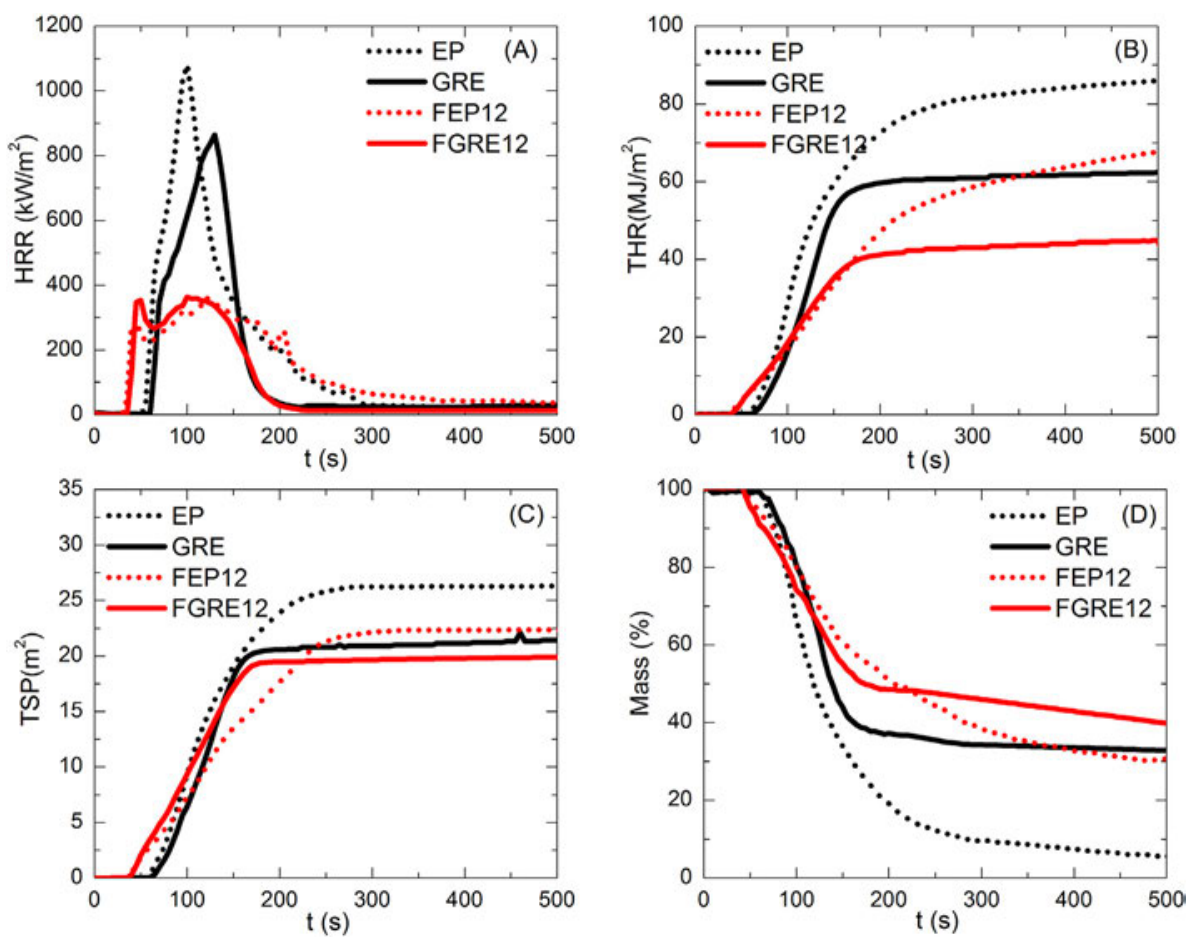

Fig. 1. The characteristic curves of EP, GRE, FEP and FGRE: A HRR vs time; B: THR vs time; C: TSP vs time; D: Mass vs time.

Table 2

The related data for EP, FEP, GRE and FGRE from cone calorimeter test at $50 \mathrm{~kW} / \mathrm{m}^{2}$

\begin{tabular}{|c|c|c|c|c|c|c|c|}
\hline Sample & $\operatorname{TTI}^{\mathrm{a}}(\mathrm{s})$ & $\mathrm{pHRR}^{\mathrm{b}}\left(\mathrm{kW} / \mathrm{m}^{2}\right)$ & $\operatorname{THR}^{\mathrm{c}}\left(\mathrm{MJ} / \mathrm{m}^{2}\right)$ & Avg. $\mathrm{EHC}^{\mathrm{d}}(\mathrm{MJ} / \mathrm{kg})$ & Avg. $\operatorname{COY}^{\mathrm{e}}(\mathrm{kg} / \mathrm{kg})$ & Avg. $\mathrm{CO}_{2} \mathrm{Y}^{\mathrm{f}}(\mathrm{kg} / \mathrm{kg})$ & Residue (wt\%) \\
\hline $\mathrm{EP}$ & $53 \pm 2$ & $1076 \pm 100$ & $91 \pm 1$ & 22.0 & 0.07 & 1.79 & $9 \pm 3$ \\
\hline FEP5 & $50 \pm 2$ & $469 \pm 60(\downarrow 56 \%)$ & $75 \pm 2$ & 19.0 & 0.10 & 1.40 & $24 \pm 2$ \\
\hline FEP8 & $45 \pm 3$ & $405 \pm 50(\downarrow 62 \%)$ & $71 \pm 1$ & 20.7 & 0.08 & 1.51 & $26 \pm 2$ \\
\hline FEP12 & $39 \pm 4$ & $363 \pm 45(\downarrow 66 \%)$ & $68 \pm 2$ & 18.1 & 0.10 & 1.28 & $25 \pm 3$ \\
\hline GRE & $65 \pm 3$ & $864 \pm 80$ & $56 \pm 3$ & 21.0 & 0.06 & 1.58 & $38 \pm 4$ \\
\hline FGRE12 & $40 \pm 2$ & $400 \pm 50(\downarrow 54 \%)$ & $41 \pm 1$ & 17.3 & 0.07 & 1.21 & $48 \pm 3$ \\
\hline
\end{tabular}

a TTI was time to ignition.

b pHRR was peak of heat release rate.

c THR was total heat release.

d Avg. EHC was the average effective heat of combustion.

e Avg. COY was average carbon monoxide yield.

${ }^{f} \mathrm{Avg}$. $\mathrm{CO}_{2} \mathrm{Y}$ was average carbon dioxide yield.

of FEP showed a sharp decrease of pHRR and widen HRR peak after FEP was ignited. In Fig. 1 (A), HRR curve of FEP12 showed a shoulder peak around $50 \mathrm{~s}$. This phenomenon also showed on HRR curves of FEP5 and FEP8. pHRRs of FEP5, FEP8 and FEP12 decreased by 56\%, $62 \%$ and $66 \%$, respectively in comparison with that of EP. THR of FEP showed the similar trend compared with that of EP. The results showed that the addition of P MA reduced the heat release of EP during burning behavior, which was beneficial for decreasing the fire hazard.

The smoke release and mass loss of EP were suppressed after the addition of P MA. In Fig. 1 (C), the rate and production of smoke release of FEP12 were lower than those of EP. Among the released gases, avg. $\mathrm{CO}_{2} \mathrm{Y}$ decreased, whereas avg. COY increased after adding P MA into EP. It was caused by the incomplete combustion behavior of FEP, which was indicated by the reduced avg. EHC of FEP in comparison with EP. These results evidently indicated that the addition of $P$ MA reduced the combustion efficiency of EP. In Fig. 1 (D), FEP12 showed lower mass loss rate and higher residue amount in comparison with EP. In Table 2, residue of FEP12 was $25 \pm 3$ wt\% which was higher $16 \mathrm{wt} \%$ than that of EP. Residue of
FEP8 was the highest amount ( $26 \pm 2$ wt\%) in EP and FEP. Seen from the residue images in Fig. 2, the residue of EP was few, whereas FEP12 formed intumescent residue during burning behavior. The latter residue was favor of retarding heat and gas exchanges be tween inner and outer of FEP.

The burning behavior of GRE was similar with that of EP in cone calorimeter test. TTI of FGRE12 was shortened 25 s compared with that of GRE. HRR curve of GRE showed one sharp peak with a pHRR value of $864 \pm 80 \mathrm{~kW} / \mathrm{m}^{2}$. It was lowered by $20 \%$ than that of EP. THR of GRE was $56 \mathrm{MJ} / \mathrm{m}^{2}$. In addition, TTI of GRE was longer $12 \mathrm{~s}$. As expected, FGRE showed remarkable improved flame retardancy in comparison with GRE in cone calorimeter test. A shoulder peak appeared around $55 \mathrm{~s}$ with low peak value of $350 \mathrm{~kW} / \mathrm{m}^{2}$ on HRR curve in Fig. 1 (A) pHRR of FGRE12 was $400 \pm 50 \mathrm{~kW} / \mathrm{m}^{2}$ which was lower by $54 \%$ than that of GRE. THR of FGRE12 was decreased from $56 \pm 3 \mathrm{MJ} / \mathrm{m}^{2}$ to $41 \mathrm{MJ} / \mathrm{m}^{2}$. Meanwhile, the smoke release was suppressed in FGRE12, as shown in Fig. 1 (C). During the burning behavior, avg. $\mathrm{CO}_{2} \mathrm{Y}$ of FGRE12 decreased, whereas avg. COY increased slightly. Avg. EHC of FGRE12 was $17.3 \mathrm{MJ} / \mathrm{kg}$, indicating that the burning efficiency of FGRE12 was lower than that of GRE in 


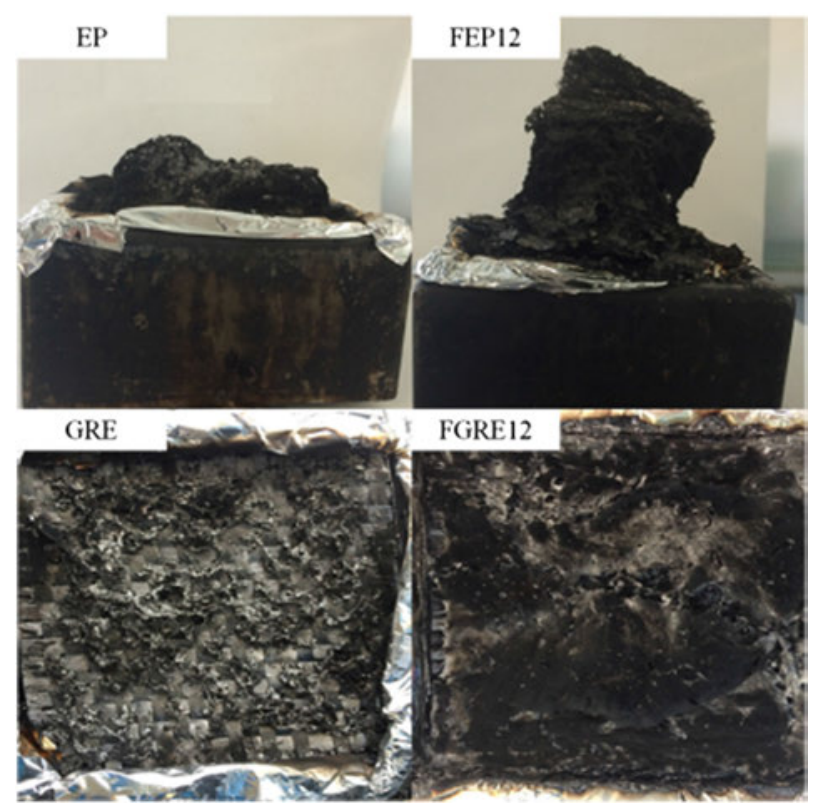

Fig. 2. Images of residue of EP, GRE, FEP12 and FGRE12 after cone calorimeter test.

cone calorimeter test. After the test, the char residue amount of FGRE12 was $48 \pm 3$ wt\%.

Fig. 2 listed the char images of residue formed by GRE and FGRE12 in cone calorimeter test. There were few residues formed from the combustion of GRE. The glass fiber woven was visible. The residue image of FGRE12 showed a thin sheet of residue from epoxy composition.

Seen from the above results, the influence of $P$ MA on pHRR in EP was more significant than that in GRE. pHRR of EP was decreased by $66 \%$, while that of GRE was decreased by $54 \%$ at $12 \mathrm{wt} \%$ loading in EP matrix. Moreover, the char residue of FEP12 increased by $16 \mathrm{wt} \%$, while that of FGRE12 increased by $10 \mathrm{wt} \%$ in comparison with EP and GRE respectively.

\subsubsection{Flame retardant mechanism}

From above results, the flame retardancy of GRE and EP was improved significantly, which was reflected by the increased LOI, self extinguishing ability in UL 94 test and the decreased pHRR in cone calorimeter test. The flame retardant mechanism was deserved to be proposed. As to EP, P MA was considered to be acted both in gas and condensed phase. Flame inhibition was the main effect in gas phase. PO - radicals were released during thermal decomposition of P MA [9]. $\mathrm{H}$ - and $\mathrm{OH}$ - radicals were able to be captured by $\mathrm{PO}$ - radicals. The reduction of $\mathrm{H}$. and $\mathrm{OH}$ - radicals retarded the formation of continuous flame environment without force fire source. In condensed phase, the addition of $\mathrm{P} \mathrm{MA}$ accu mulated the formation of char residue of EP owing to the phos phorous acid compounds from thermal decomposition of P MA. On one side, the amounts of char residue of FEP were much higher than that of EP. On another side, an intumescent residue formed because the gaseous products evolved from the thermal decomposition of FEP. This type of residue was able to isolate the gas and heat ex changes, which meant to suppress the burning behavior of EP matrix. As to GRE, the flame inhibition and accumulating char formation effects of P MA were also showed for EP matrix. How ever, the flame retardant efficiency in GRE was not as strong as that in EP.

\subsection{Influence of $P$ MA on the mechanical behavior of EP and GRE}

\subsubsection{DMA test}

Dynamic temperature spectra of storage modulus $\left(E^{\prime}\right)$, loss modulus $\left(\mathrm{E}^{\prime \prime}\right)$ and loss factor $(\tan \delta)$ were illustrated in Fig. 3(A, B and $C$ ). The plots of peak height of $\log \left(E^{\prime \prime}\right)$ against $P$ MA loading of EP and GRE were showed in Fig. 3(D). Data of Tg (glass transition temperature) and $\tan \delta_{\max }$ were listed in Table 3. Tg was temper ature at the peak of $\tan \delta\left(\tan \delta_{\max }\right)$ in this work.

In Fig. 3(A), dynamic temperature spectra of $E^{\prime}, E^{\prime \prime}$ and $\tan \delta$ of EP was divided as glassy and elastomeric states according to the movements of macromolecular chains under heating. $\mathrm{E}^{\prime}$ of $\mathrm{EP}$ significantly increased after the addition of glass fiber woven over the whole temperature spectra. The increase of $E^{\prime}$ was caused by the high strength of glass fiber. In Fig. 3(B and D), GRE showed a broader and higher $\mathrm{E}^{\prime \prime}$ peak than that of EP, which meant that the internal friction was also enhanced in GRE. Moreover, $\tan \delta_{\max }$ of GRE decreased from $0.84 \pm 0.01$ to $0.39 \pm 0.02$ due to the interface friction between matrix and glass fiber. In addition, both GRE and EP showed high $\mathrm{Tg}$ temperature of $197^{\circ} \mathrm{C}$.

In this segment, the effectiveness co efficient $C[20,21]$ was calculated in order to evaluate influences of P MA on $E^{\prime}$ of GRE. The effectiveness of P MA was low if the value of the constant $C$ was high. The expression of effectiveness co efficient $C$ was in the following:

$$
\text { C } \frac{\left(E_{G}^{\prime} / E_{R}^{\prime}\right)_{G R E}}{\left(E_{G}^{\prime} / E_{R}^{\prime}\right)_{E P}},
$$

where $E_{G}^{\prime}$ and $E_{R}^{\prime}$ were $E^{\prime}$ on glassy and elastomeric region, respectively. According to $E^{\prime}$ spectra in Fig. $3(A), E_{G}^{\prime}$ and $E_{R}^{\prime}$ were chosen at 40 and $200{ }^{\circ} \mathrm{C}$ respectively for EP, FEP, GRE and FGRE. All calculated constant $C$ were listed in Table 3. $C$ of GRE was 0.17. After the addition of $P$ MA, $C$ values of FGRE decreased, indicating that the addition of P MA in EP improved the $E^{\prime}$ of GRE. This improve ment on $\mathrm{E}^{\prime}$ was considered to be attributed to that the polar groups on P MA structure increased the intra molecular forces inside epoxy matrix. Tg of FEP and FGRE were brought to lower temper ature and $\tan \delta_{\max }$ increased in comparison with EP and GRE. These phenomenon revealed that the cross linking density of EP and GRE was decreased due to the addition of $P$ MA. It was explained by that P MA had two effective functionality of $\mathrm{N}-\mathrm{H}$ which was able to react with epoxy, whereas the curing agent DDS had four effective functionality. The less effective functionality meant that the less cross linking points formed in EP. Fig. 3(D) showed that the peak of $E^{\prime \prime}$ kept at the same level when the loading of P MA increased for both EP and GRE. It meant that friction effect had almost no augment or reduction after the addition of P MA into EP and GRE. This phenomenon indicated that the interface between EP matrix and glass fiber might not change significantly after the addition of P MA.

\subsubsection{Nanoindentation test}

According to DMA results of EP and FEP in 3.2.1, EP and FEP12 were chosen for a comparative nanoindentation study on me chanical properties between EP and FEP in nano scale. Fig. 4(A and B) showed the representative nanoindentation force penetration depth curves and Young's modulus \& hardness of EP and FEP, respectively. The insert figure in Fig. 4(A) showed the nano indentation imprints after test.

The results revealed that $\mathrm{P}$ MA showed minor enhancement influences on mechanical properties of EP. Specifically, Young's modulus of FEP12 increased from $3.83( \pm 0.13)$ GPa to $4.11( \pm 0.03)$ GPa and the hardness increased from $317.0( \pm 4.6) \mathrm{MPa}$ to 334.0 $( \pm 4.7) \mathrm{MPa}$ in comparison with that of EP. The minor enhancements 

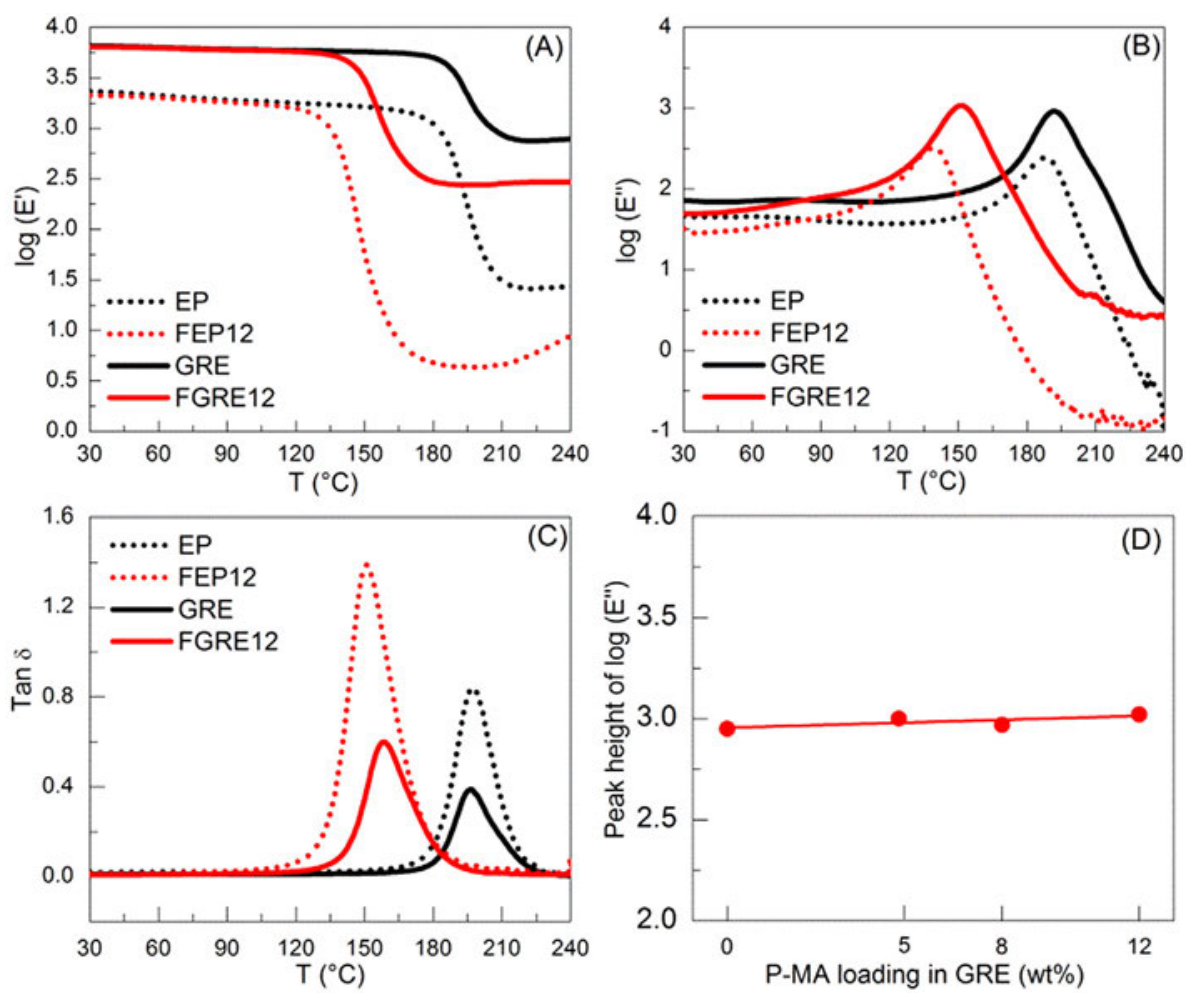

Fig. 3. (A): $\log \left(E^{\prime}\right)$ curves; (B): $\log \left(E^{\prime \prime}\right)$ curves; $\left.C\right)$ : Tan $\delta$ curves of EP, FEP12, GRE and FGRE12; D): the relationship between peak height of log (E') and P-MA loading.

Table 3

The constant $\mathrm{C}$, $\tan \delta_{\max }$ and Tg of EP, GRE, FEP and FGRE.

\begin{tabular}{llll}
\hline Sample & $\mathrm{C}$ & $\operatorname{Tan} \delta_{\max }$ & $\operatorname{Tg}\left({ }^{\circ} \mathrm{C}\right)$ \\
\hline EP & & $0.84 \pm 0.01$ & $197 \pm 4$ \\
FEP5 & & $1.03 \pm 0.01$ & $172 \pm 4$ \\
FEP8 & $0.94 \pm 0.01$ & $165 \pm 4$ \\
FEP12 & $1.39 \pm 0.01$ & $151 \pm 4$ \\
GRE & & $0.39 \pm 0.02$ & $197 \pm 5$ \\
FGRE5 & 0.17 & $0.59 \pm 0.01$ & $174 \pm 6$ \\
FGRE8 & 0.10 & $0.57 \pm 0.01$ & $165 \pm 5$ \\
FGRE12 & 0.16 & $0.60 \pm 0.01$ & $159 \pm 6$ \\
\hline
\end{tabular}

were explained by that the polar groups in the structure of P MA produced high intra molecular forces inside EP. The high intra molecular forces induced small strain when the materials suffer a stress, which reflected with higher Young's modulus and hardness.

\subsubsection{Fiber push in and three point bending tests}

Accompanied by the incorporation of glass fiber cloth, the EP/ glass fiber interface formed in GRE. The interfacial behavior of polymer composites had been studied systematically by some nano mechanical techniques, such as push in, push out, etc. $[18,21]$. In this work, the influences of P MA on interface properties of GRE were studied by fiber push in test and three bending test in nano and macro scale, respectively.

Fiber push in tests of GRE and FGRE12 were carried out in order to evaluate the interface strength in nano scale. As was shown in Fig. 5(A), the representative push in results of GRE showed nearly overlapped force penetration depth response. The glass fiber was clearly de bonded from EP matrix which was showed by the insert figure in Fig. 5(A). The strain burst at large penetration depth
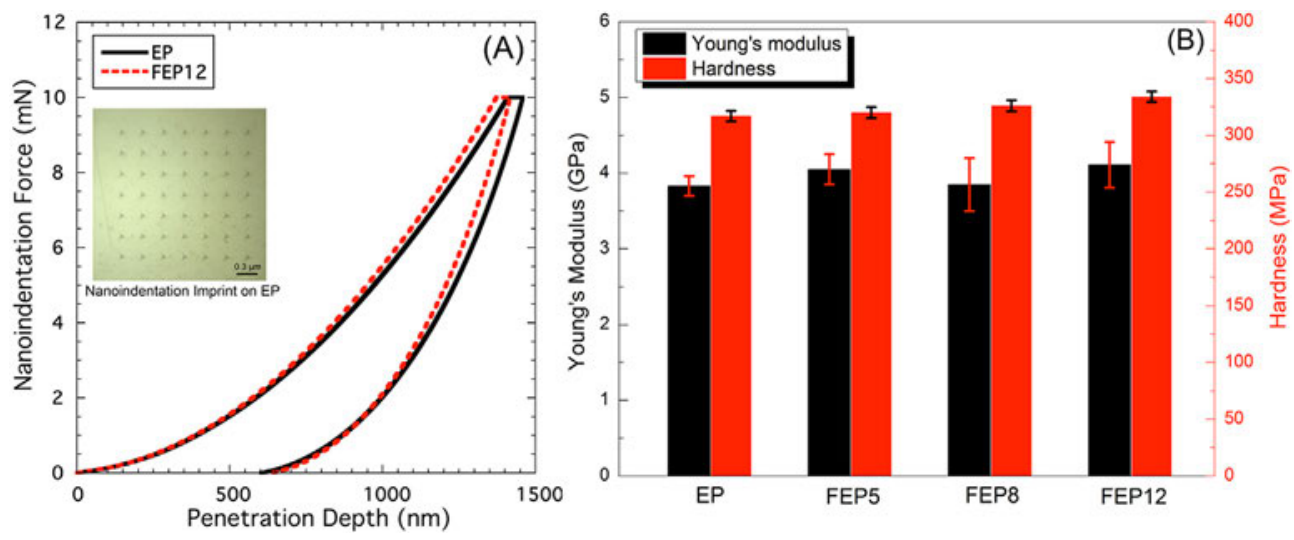

Fig. 4. (A) Representative nanoindentation force-penetration depth curves of EP and FEP12; (B) Comparisons of Young's modulus and hardness of EP and FEP. 

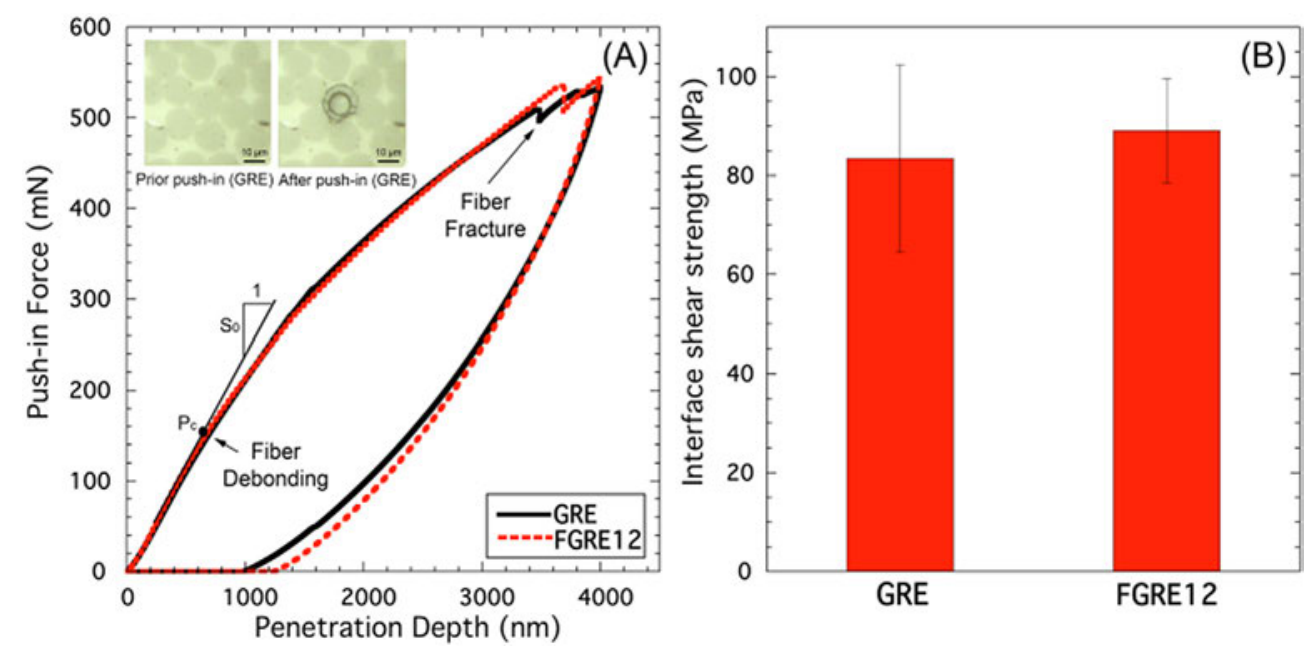

Fig. 5. (A) Representative push-in force-penetration depth of GEP and GFEP12; (B) Interface shear strength of GEP and FGRE12.

represented the failure of glass fiber around the punch imprint.

Based on shear lag model, interfacial shear strength $\tau$ of GRE was extracted by the following formula:

$$
\tau \quad \frac{S_{0} P_{C}}{2 \pi^{2} r^{3} E_{f}}
$$

where $S_{0}$ and $P c$ were initial stiffness and critical de bonding load, respectively, measured from the force penetration depth curves. The determination of $P c$ followed the methodology in Reference $[18,22]$; $r$ was the fiber radius, which was $\sim 7 \mu \mathrm{m}$; $\mathrm{E}_{\mathrm{f}}$ was the lon gitudinal Young's modulus of glass fiber, which was chosen as $80 \mathrm{GPa}$, which was tested by nanoindentation. According to the above formula of $\tau$, IFSS of GRE and FGRE12 were $83.5( \pm 19) \mathrm{MPa}$ and $89.1( \pm 11) \mathrm{MPa}$, respectively. The results indicated that P MA showed minor influences on interfacial properties of GRE in nano scale.

Fig. 6(A) showed the representative macro interlaminar shear stress vs displacement curves of GRE and FGRE12 tested by three point bending test. As expected, P MA also induced negligible in fluences on the macro scale mechanical properties of GRE, as evi denced by the comparable maximum interlaminar shear stresses of GRE and FGRE12. The interlaminar shear strength of GRE and FGRE12 were $43.5( \pm 10)$ and $43.6( \pm 9.5)$ MPa respectively, which were almost the same value. After the maximum shear stress reached, both GRE and FGRE12 experienced gradual strain soft ening coupled with stress bursts at large displacements. These stress bursts were originated by cracking either in EP, EP/glass fiber interfaces or glass fibers. Due to the brittle nature of EP and glass fiber, it was considered that the moderate EP/glass fiber interfacial interaction contributed dominantly to the toughening properties of GRE and FGRE12. It was further validated by the similar fracture morphology characterizations of GRE and FGRE12 after composite failures, which was shown in Fig. 6(B and C).

\subsection{Influence of $P$ MA on thermal stability of EP and GRE}

In this segment, the influence of flame retardant P MA on

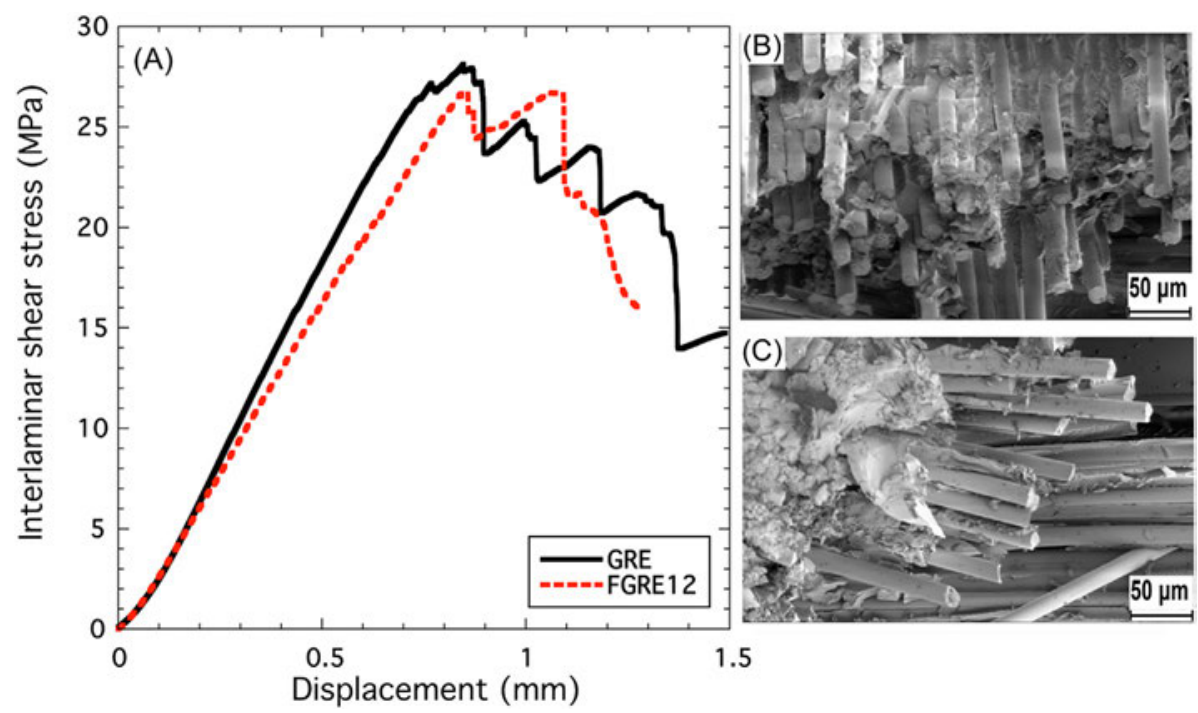

Fig. 6. (A) Interlaminar shear stress versus displacement curves of GRE and FGRE12; (B) Fracture morphology of GRE after the composite failure; (C) Fracture morphology of FGRE12 after composite failure. 
thermal stability of EP and GRE was studied by TGA under nitrogen atmosphere $\left(\mathrm{N}_{2}\right)$. The thermal weight loss vs temperature curves (TGA) and derivative thermal gravimetric (DTG) curves were pre sented in Fig. 7 and the related data were collected in Table $4 . \mathrm{T}_{\mathrm{d} 5 \%}$ meant the temperature when the weight loss was 5\%, which rep resented the onset decomposition temperature. $T_{\max }$ meant the temperature at maximum decomposition rate, subtracted from DTG curves. In this work the difference between $\mathrm{T}_{\mathrm{d} 5 \%}$ and $\mathrm{T}_{\max }(\Delta \mathrm{T})$ was used to evaluate the decomposing rate of EP, FEP, GRE and FGRE [23].

EP decomposed initially at $383{ }^{\circ} \mathrm{C}$ and then the decomposing process went fast accompanied by the formation of char residue. $\mathrm{T}_{\max }$ of EP was at $408{ }^{\circ} \mathrm{C}$. The residue was $15.6 \mathrm{wt} \%$ at $700{ }^{\circ} \mathrm{C}$. From Fig. 7 and Table 4, the addition of P MA brought $T_{d 5 \%}$ and $T_{\max }$ of EP to lower temperatures. This effect was enhanced along with the rising of $\mathrm{P}$ MA loading. $\mathrm{T}_{\mathrm{d} 5 \%}$ of FEP12 was lower $58{ }^{\circ} \mathrm{C}$ than that of EP. Meanwhile, $\mathrm{T}_{\max }$ was lower $52{ }^{\circ} \mathrm{C}$. However, the addition of $\mathrm{P}$ MA greatly slowed the decomposing rate and increased the residue amount at high temperature. $\triangle$ T of FEP5, FEP8 and FEP12 was 40, 42 and $37{ }^{\circ} \mathrm{C}$ respectively which were much wider than that of EP $\left(25{ }^{\circ} \mathrm{C}\right)$. Moreover, FEP5 showed $25.4 \%$ residue amount, which increased by $63 \%$ compared with EP at $700{ }^{\circ} \mathrm{C}$. The residues of FEP8 and FEP12 were less than that of FEP5, indicating that the effect of $P$ MA on accelerating char formation was not proportional with the loading of P MA. However, the residues still increased by $49 \%$ and $39 \%$ separately compared with $\mathrm{EP}$ at $700^{\circ} \mathrm{C}$. The lower temperature of $\mathrm{T}_{\mathrm{d} 5 \%}$ and $\mathrm{T}_{\max }$ of FEP were caused by the low thermal stability of flame retardant $\mathrm{P}$ MA. The decomposition of $\mathrm{P}$ MA produced acid compounds which was able to accelerate the formation of char residue. When the fresh residue was formed on surface of sample at certain temperature, it decreased the heat and gas exchange effi ciency between inner and outer of sample. The decomposing rate was slowed down owing to this effect. However, the fresh residue was unstable and destroyed when temperature increased. There fore the decomposition went ahead again. Moreover, the phos phoric acid formed during the decomposing of $\mathrm{P}$ MA accumulated the formation of char residue which is the main composition of residue at high temperature.

In this work, the content of glass fiber was kept around $30 \mathrm{wt} \%$ in GRE and FGRE, which was tested with TGA curves under air at mosphere (shown in Supplementary document). From Table 4, the

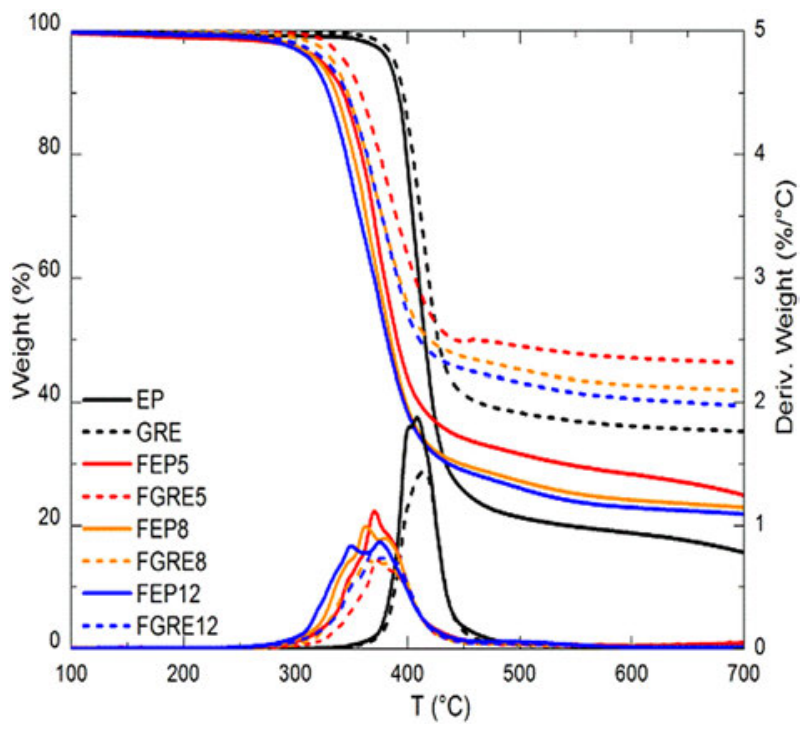

Fig. 7. TGA and DTG curves of EP, GRE, FEP and FGRE under $\mathrm{N}_{2}$.
Table 4

TGA data of EP, GRE, FEP and FGRE.

\begin{tabular}{|c|c|c|c|c|c|}
\hline \multirow[t]{2}{*}{ Samples } & \multirow[t]{2}{*}{$\mathrm{T}_{\mathrm{d} 5 \%^{\mathrm{a}}\left({ }^{\circ} \mathrm{C}\right)}$} & \multirow[t]{2}{*}{$\mathrm{T}_{\max }^{\mathrm{b}}\left({ }^{\circ} \mathrm{C}\right)$} & \multirow[t]{2}{*}{$\Delta \mathrm{T}^{\mathrm{C}}\left({ }^{\circ} \mathrm{C}\right)$} & \multicolumn{2}{|c|}{$\begin{array}{l}\text { Residue } \\
\left(700^{\circ} \mathrm{C} \text {, wt } \%\right)\end{array}$} \\
\hline & & & & Exp. & Cal. \\
\hline $\mathrm{EP}$ & 383 & 408 & 25 & 15.6 & \\
\hline FEP5 & 330 & 370 & 40 & 25.4 & \\
\hline FEP8 & 321 & 363 & 42 & 23.3 & \\
\hline FEP12 & 315 & 352 & 37 & 21.7 & \\
\hline GRE & 389 & 415 & 26 & 35.3 & 40.9 \\
\hline FGRE8 & 334 & 367 & 33 & 41.8 & 46.3 \\
\hline FGRE5 & 346 & 371 & 27 & 46.4 & 47.5 \\
\hline FGRE12 & 325 & 356 & 31 & 39.7 & 45.2 \\
\hline
\end{tabular}

${ }^{a} T_{d 5 \%}$ meant the temperature when the weight loss was $5 \%$.

b $\mathrm{T}_{\max }$ meant the temperature at maximum decomposition rate.

c $\Delta \mathrm{T}$ was the difference between $\mathrm{a}$ and $\mathrm{b}$.

addition of glass fiber improved the initial thermal stability of EP. $\mathrm{T}_{\mathrm{d} 5 \%}$ and $\mathrm{T}_{\max }$ of GRE were higher 6 and $7{ }^{\circ} \mathrm{C}$ than those of EP separately. $\Delta \mathrm{T}$ of GRE was $26^{\circ} \mathrm{C}$, indicating that glass fiber showed almost no influence on thermal decomposition rate of EP. However, the addition of glass fiber reduced the formation of residue at high temperature. In order to compare the residue amount before and after prepared GRE and FGRE, the calculated residue amount fol lowed the formula:

$R_{\text {cal. }} \quad R_{E P} \times W_{E P}+R_{\text {fiber }} \times W_{\text {fibre }}$

$\mathrm{R}_{\mathrm{EP}}$ meant the char residue of epoxy at $700{ }^{\circ} \mathrm{C}$; $\mathrm{R}_{\text {fiber }}$ meant the residue of glass fiber at $700{ }^{\circ} \mathrm{C}(100 \mathrm{wt} \%)$. The calculated residue amount of GRE was $40.9 \%$, while the experimental residue amount was only $35.3 \%$ at $700{ }^{\circ} \mathrm{C}$.

The addition of flame retardant P MA showed similar influences on thermal stability of GRE as compared to the unfilled epoxy system. $\mathrm{T}_{\mathrm{d} 5 \%}$ and $\mathrm{T}_{\max }$ of FGRE were lower in comparison with GRE. For instance, $\mathrm{T}_{\mathrm{d} 5 \%}$ and $\mathrm{T}_{\max }$ of FGRE5 were at 334 and $367^{\circ} \mathrm{C}$ which were lower 55 and $48^{\circ} \mathrm{C}$ respectively in comparison with GRE. $\Delta \mathrm{T}$ values of FGRE were close to that of GRE. Compared with $\triangle T$ of EP and FEP, the impact of $P$ MA on decreasing decomposing rate in GRE was not as well as that in EP. The residue of GRE and FGRE showed a sequence at $700{ }^{\circ} \mathrm{C}$ : FGRE5 $>$ FGRE8 $>$ FGRE12 $>$ GRE. FGRE5 showed highest residue amount of $46.4 \%$. However, the enhancement of P MA on residue formation of GRE weakened from the comparison between FEP and the corresponding FGRE. The calculated residue amount of FGRE12 was $45.2 \%$, but the experi mental value was only $39.7 \%$. This situation also occurred for FGRE5 and FGRE8. The reason was considered to be caused by that the glass fiber retarded the residue formed on samples.

\section{Conclusions}

In this work, flame retardant glass fiber reinforced epoxy composites (FGRE) were prepared via adding flame retardant P MA into GRE. The flammability of GRE was reduced significantly due to the addition of P MA. LOI of FGRE was increased significantly in comparison with GRE. FGRE8 increased from 25\% (LOI of GRE) to 31\%. The addition $\mathrm{f}$ P MA endowed GRE with strong self extinguishing ability. FGRE12 passed V 0 rating in UL 94 test. In addition, pHRR of FGRE12 showed 54\% reduction in comparison with GRE. As to EP matrix, LOI of FEP12 was 36\%. pHRR of FEP12 was $66 \%$ reduction in comparison with that of EP. The influence of $P$ MA on flame retardancy in GRE was not as well as that in EP. For instance, the reduction of PHRR in FEP12 was higher than that in GRE. In TGA test, the char residue of FGRE was higher than that of GRE, while the amounts were lower than those of calculated values 
according to the char residue amounts of FEP. It indicated that the influence of P MA on charring ability of GRE was not as well as that of EP. Moreover, the addition of $\mathrm{P}$ MA showed positive effect on the interfacial properties between epoxy matrix and glass fiber. IFSS of GRE and FGRE12 were $83.5( \pm 19) \mathrm{MPa}$ and $89.1( \pm 11) \mathrm{MPa}$, respectively in fiber push in test. The interlaminar shear strength of GRE and FGRE12 were $43.5( \pm 10.0)$ and $43.6( \pm 9.5)$ MPa respec tively, which were almost the same value in three points bending test. The results showed that the interfacial property of FGRE was kept at the same level with that of GRE.

\section{Acknowledgements}

One of our authors (Ms. Xiaomin Zhao) would thank the financial support from China Scholarship Council (201206230082). In addition, this work is funded by Spanish Ministry of Economy and Competitiveness (MINECO) under Ramón y Cajal fellowship (RYC 2012 10737). We also thank the EU COST network CM1302 "Smart Inorganic Polymers" (SIPs).

\section{References}

[1] Ramesh M, Palanikumar K, Reddy KH. Mechanical property evaluation of sisal jute glass fiber reinforced polyester composites. Compos Part B Eng 2013;48:1 9.

[2] Fan Z, Santare MH, Advani SG. Interlaminar shear strength of glass fiber reinforced epoxy composites enhanced with multi-walled carbon nanotubes. Compos Part A Appl Sci Manuf 2008;39:540 54.

[3] Lim WP, Mariatti M, Chow W, Mar K. Effect of intumescent ammonium polyphosphate (APP) and melamine cyanurate (MC) on the properties of epoxy/ glass fiber composites. Compos Part B Eng 2012;43:124 8.

[4] Wang X, Song L, Pornwannchai W, Hu Y, Kandola B. The effect of graphene presence in flame retarded epoxy resin matrix on the mechanical and flammability properties of glass fiber-reinforced composites. Compos Part A Appl Sci Manuf 2013;53:88 96.

[5] Wu Q, Zhu W, Zhang C, Liang Z, Wang B. Study of fire retardant behavior of carbon nanotube membranes and carbon nanofiber paper in carbon fiber reinforced epoxy composites. Carbon 2010;48:1799 806.

[6] Bozkurt E, Kaya E, Tanoğlu M. Mechanical and thermal behavior of non-crimp glass fiber reinforced layered clay/epoxy nanocomposites. Compos Sci Technol 2007;67:3394 403 .

[7] Kandola BK, Horrocks AR, Myler P, Blair D. New developments in flame retardancy of glass-reinforced epoxy composites. J Appl Polym Sci 2003;88: 251121
[8] Jiang J, Cheng Y, Liu Y, Wang Q, He Y, Wang B. Intergrowth charring for flameretardant glass fabric-reinforced epoxy resin composites. J Mater Chem A 3 2015:428490.

[9] Zhao X, Vignesh H, Llorca J, Wang D-Y. Impact of halogen-free flame retardant with varied phosphorus's chemical surrounding on the properties of diglycidyl ether of bisphenol-A type epoxy resin: synthesis, fire behaviour, flameretardant mechanism and mechanical properties. RSC Adv 2016;6:59226 36.

[10] Schartel B. Phosphorus-based flame retardancy mechanisms old hat or a starting point for future development? Materials 2010;3:4710 45.

[11] Chen W, Liu P, Liu Y, Wang Q. Interfacial carbonation for efficient flame retardance of glass fiber-reinforced polyamide 6. Polym Chem 2015;6: 440914.

[12] Li Z, Yang R. Study of the synergistic effect of polyhedral oligomeric octadiphenylsulfonylsilsesquioxane and 9, 10-dihydro-9-oxa-10phosphaphenanthrene-10-oxide on flame-retarded epoxy resins. Polym Degrad Stab 2014;109:2339.

[13] Kandola BK, Luangtriratana P, Duquesne S, Bourbigot S. The effects of thermophysical properties and environmental conditions on fire performance of intumescent coatings on glass fibre-reinforced epoxy composites. Materials 2015;8:5216 37.

[14] Chen X, Yuan L, Zhang Z, Wang H, Liang G, Gu A. New glass fiber/bismaleimide composites with significantly improved flame retardancy, higher mechanical strength and lower dielectric loss. Compos Part B Eng 2015;71:96 102.

[15] Zhang Z, Yuan L, Liang G, Gu A. A strategy and mechanism of fabricating flame retarding glass fiber fabric reinforced vinyl ester composites with simultaneously improved thermal stability, impact and interlaminar shear strengths. Polym Degrad Stab 2016;125:49 58.

[16] Petersen MR, Chen A, Roll M, Jung S, Yossef M. Mechanical properties of fireretardant glass fiber-reinforced polymer materials with alumina tri-hydrate filler. Compos Part B Eng 2015:78:109 21.

[17] Oliver WC, Pharr GM. Measurement of hardness and elastic modulus by instrumented indentation: advances in understanding and refinements to methodology. J Mater Res 2004;19:3 20.

[18] Rodriguez M, Molina-Aldareguía JM, González C, LLorca J. A methodology to measure the interface shear strength by means of the fiber push-in test. Compos Sci Technol 2012;72:1924 32.

[19] Schartel B, Bartholmai M, Knoll U. Some comments on the use of cone calorimeter data. Polym Degrad Stab 2005;88:540 7.

[20] Pothan LA, Oommen Z, Thomas S. Dynamic mechanical analysis of banana fiber reinforced polyester composites. Compos Sci Technol 2003:63:283 93.

[21] Tan JK, Kitano T, Hatakeyama T. Crystallization of carbon fibre reinforced polypropylene. J Mater Sci 1990;25:3380 4.

[22] Medina C, Molina-Aldareguía JM, González C, Melendrez MF, Flores P, LLorca J. Comparison of push-in and push-out tests for measuring interfacial shear strength in nano-reinforced composite materials. J Compos Mater 2015;50: 1651 9. 0021998315595115.

[23] Hesami M, Bagheri R, Masoomi M. Combination effects of carbon nanotubes, MMT and phosphorus flame retardant on fire and thermal resistance of fiberreinforced epoxy composites. Iran Polym J 2014;23:469 76. 